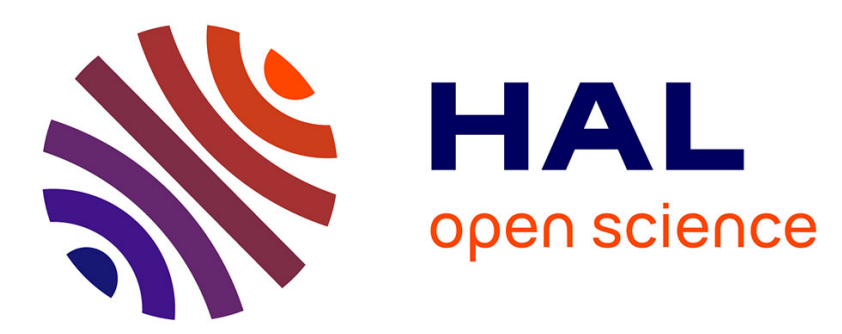

\title{
Mechanical Behavior of Ti-6Al-2Sn-4Zr-2Mo Titanium Alloy under Hot and Superplastic Forming Conditions: Experiment and Modeling
}

Gen Yamane, Vincent Velay, Vanessa Vidal, Hiroaki Matsumoto

\section{- To cite this version:}

Gen Yamane, Vincent Velay, Vanessa Vidal, Hiroaki Matsumoto. Mechanical Behavior of Ti-6Al-2Sn4Zr-2Mo Titanium Alloy under Hot and Superplastic Forming Conditions: Experiment and Modeling. ICSAM 2018 - 13th International Conference on Superplasticity in Advanced Materials, Aug 2018, St Petersbourg, Russia. pp.413-418, 10.4028/www.scientific.net/DDF.385.413 . hal-01864430

\section{HAL Id: hal-01864430 \\ https://hal.science/hal-01864430}

Submitted on 8 Feb 2020

HAL is a multi-disciplinary open access archive for the deposit and dissemination of scientific research documents, whether they are published or not. The documents may come from teaching and research institutions in France or abroad, or from public or private research centers.
L'archive ouverte pluridisciplinaire HAL, est destinée au dépôt et à la diffusion de documents scientifiques de niveau recherche, publiés ou non, émanant des établissements d'enseignement et de recherche français ou étrangers, des laboratoires publics ou privés. 


\title{
Mechanical Behavior of Ti-6Al-2Sn-4Zr-2Mo Titanium Alloy under Hot and Superplastic Forming Conditions: Experiment and Modeling
}

\author{
YAMANE Gen ${ }^{1,2, a}$, VELAY Vincent ${ }^{2, b *}$, VIDAL Vanessa ${ }^{2, c}$, \\ and MATSUMOTO Hiroaki ${ }^{1, d}$
}

\author{
${ }^{1}$ Department of Advanced Materials Science, Faculty of Engineering, Kagawa University, 2217-20 \\ Hayashi-Cho, Takamatsu, Kagawa 761-0396, Japan \\ ${ }^{2}$ Institut Clément Ader (ICA), Université de Toulouse, CNRS, Mines Albi, UPS, INSA, \\ ISAE-SUPAERO, Campus Jarlard, 81013 Albi CT Cedex 09, France. \\ as16g571@stu.kagawa-u.ac.jp, bvincent.velay@mines-albi.fr, ${ }^{c}$ vanessa.vidal@mines-albi.fr, \\ ${ }^{d}$ matsu_h@eng.kagawa-u.ac.jp
}

Keywords: Titanium alloy, Behavior modeling, microstructural evolution, HF and SPF processes.

\begin{abstract}
Titanium alloys are widely used in the aircraft industry. In sheet form, they can be used for the manufacturing of pylon or engine parts. With the aim of achieving a cost reduction, this study proposes to act on the starting microstructure so as to improve the mechanical properties during the forming stages. In the present study, investigations are focused on Ti-6Al-2Sn-4Zr-2Mo (Ti6242) alloy, which is especially used for the hot areas (e.g. parts close to the engine or the combustion chamber). A thorough mechanical test campaign was performed on the Ti6242 alloy, examining, on the one hand, the microstructure qualified by the aircraft industry and, on the other hand, a new range of refined microstructures obtained by a hot straining process. For each test, microstructural observations exhibited complex phenomena simultaneously including both grain growth and dynamic recrystallization. The occurrence, sequencing and coupling of the mechanisms were all strongly dependent on the starting microstructure and the test conditions (time-temperature and strain rate) investigated. They are not easy to understand and require further tests and observations. In such a framework, the implementation of mechanical models is an efficient and relevant way of gaining a better knowledge of the microstructural evolution observed and its influence on the mechanical behavior.
\end{abstract}

\section{Introduction}

Ti6242 alloy is used in the aircraft industry for the manufacturing of parts that can be used for thermal protection in hot areas. Its in-service behavior at high temperature is greatly improved compared to Ti-6Al-4V alloy, which is the most conventional titanium alloy [1]. Presently, the complex shapes are obtained by a Superplastic Forming process (SPF), require high forming temperatures $\left(\geq 900^{\circ} \mathrm{C}\right)$ and are not easy to form. However, this alloy demonstrates good mechanical behavior at high temperatures and a reduced cost compared to a Nickel-based Superalloy. This work proposes to act on the starting microstructure so as to improve the mechanical properties during the forming stages. The final objectives are to decrease the forming temperature and increase the strain rate. In order to ensure this, the microstructural evolution and the deformation mechanisms acting on the mechanical behavior will be identified for a large number of test conditions. Three starting equi-axed microstructures were investigated and compared by performing a thorough test campaign, including mechanical and annealing tests. These tests examined, on the one hand, the microstructure qualified by the aircraft industry and, on the other hand, a new range of refined microstructures obtained by a hot straining process. Depending on the test conditions, microstructural observations exhibited complex phenomena, simultaneously including both grain growth $[2,3]$ and dynamic recrystallization (DRX) [4]. These phenomena greatly influence the mechanical behavior with regard to strain hardening or softening, and can drastically reduce the maximal elongation or, on the contrary, increase it. In this paper, the proposed model is able to take into account the effects of strain rate sensitivity, hardening or softening 
associated with complex microstructural evolution. The model components use several results taken from the literature to describe the material viscosity [5], the strain hardening effect due to grain growth [2] or the softening phenomenon due to $\operatorname{DRX}[4,6,7]$.

\section{Mechanical and Microstructural Investigations}

The material investigated is a near- $\alpha$ Ti6242 Titanium alloy with an equiaxed microstructure. It is a creep resistant alloy used for high temperature applications [1]. In the present work, three starting microstructures were investigated with average grain sizes of $0.8,3$ and $6 \mu \mathrm{m}$. In order to investigate the influence of the loading path on the mechanical behavior of each starting microstructure, two kinds of tests were performed. First, annealing tests allowed observation of the microstructural evolution under static conditions, e.g. evolution only due to the temperature levels and the exposure times. Secondly, dynamic tests were conducted by using a tensile test machine that gives accurate readings for the high elongations. The tests considered a furnace with three heating zones ensuring a negligible thermal gradient during the deformation process. In this case, a temperature range between $650^{\circ} \mathrm{C}$ and $960^{\circ} \mathrm{C}$ and several strain rates from $10^{-4} s^{-1}$ to $10^{-2} s^{-1}$ were considered for each starting microstructure. The static tests did not reveal significant grain size evolution for the starting microstructure of $6 \mu \mathrm{m}$ regardless of the test conditions, whereas evolution occurred for the other starting microstructures whose evolution increased with the temperature and the time. Moreover, the evolution rate was higher for the Ultra Fine Grain microstructure $(0.8 \mu \mathrm{m})$. Fig. 1 shows the grain size evolution during the annealing tests for the starting microstructure of $3 \mu \mathrm{m}$. A slight evolution can be observed below $840^{\circ} \mathrm{C}$, whereas a significant increase occurs from $920^{\circ} \mathrm{C}$.
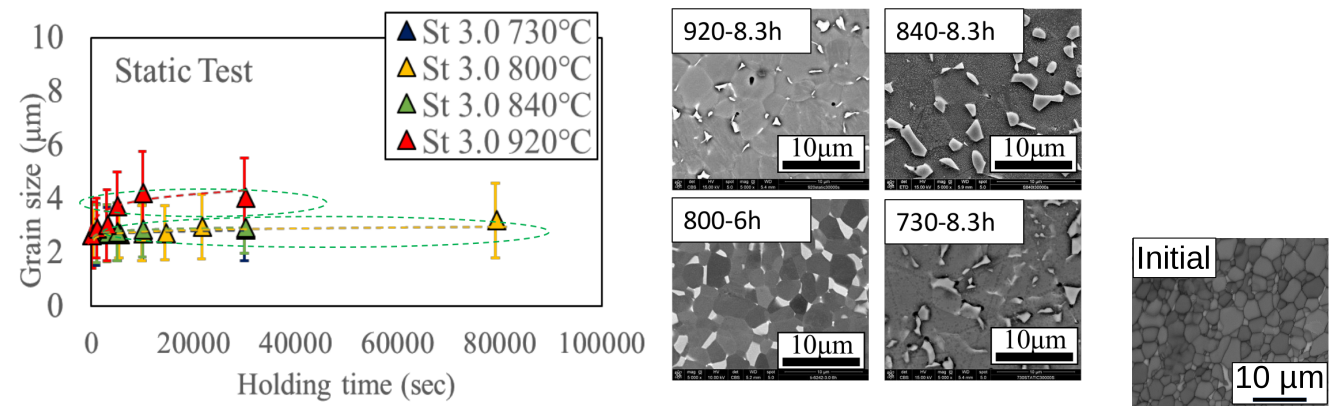

Fig. 1: Grain size evolution during the annealing tests at several temperature levels from $730^{\circ} \mathrm{C}$ to $920^{\circ} \mathrm{C}$ and an initial average grain size of $3 \mu \mathrm{m}$

The elongation tests conducted at $650^{\circ} \mathrm{C}$ and $700^{\circ} \mathrm{C}$ for the starting microstructure of $0.8 \mu \mathrm{m}$ showed a plasticity mainly governed by dislocation motion at the higher strain rate $\left(10^{-2} s^{-1}\right)$, whereas complex interactions seem to be initiated for the lower ones $\left(10^{-3} s^{-1}\right.$ and $\left.10^{-4} s^{-1}\right)$. Indeed, EBSD analysis revealed a random texture and considerable grain growth, which increased with the test temperature. Moreover, at $10^{-4} s^{-1}$, the strain-stress response exhibited a slight softening before a stationary behavior which might be due to a dynamic recrystallization effect, as shown in Fig. 2.

At $800^{\circ} \mathrm{C}$, Grain Boundary Sliding (GBS) occurred regardless of the strain rate and very significant grain coarsening was observed at the lower strain rate, inducing a strain hardening effect observed in the tensile test. Similar analysis was conducted on the starting microstructure of $3 \mu \mathrm{m}$. In this case, the material exhibited interactions between dynamic recrystallization and grain growth at intermediate temperatures $\left(730^{\circ} \mathrm{C} \leq T \leq 840^{\circ} \mathrm{C}\right)$, with grain growth predominant at $T \geq 900^{\circ} \mathrm{C}$, whereas no evolution was observed at low temperature $\left(T \leq 730^{\circ} \mathrm{C}\right)$. Lastly, the starting microstructure of $6 \mu \mathrm{m}$ shows an unexpected result with a significant grain growth $\left(700^{\circ} \mathrm{C} \leq \mathrm{T} \leq 900^{\circ} \mathrm{C}\right)$ from $10^{-2} \mathrm{~s}^{-1}$ to $10^{-3} s^{-1}$. However, a dynamic recrystallization seemed to be initiated at $5.10^{-4} s^{-1}$ after a grain 


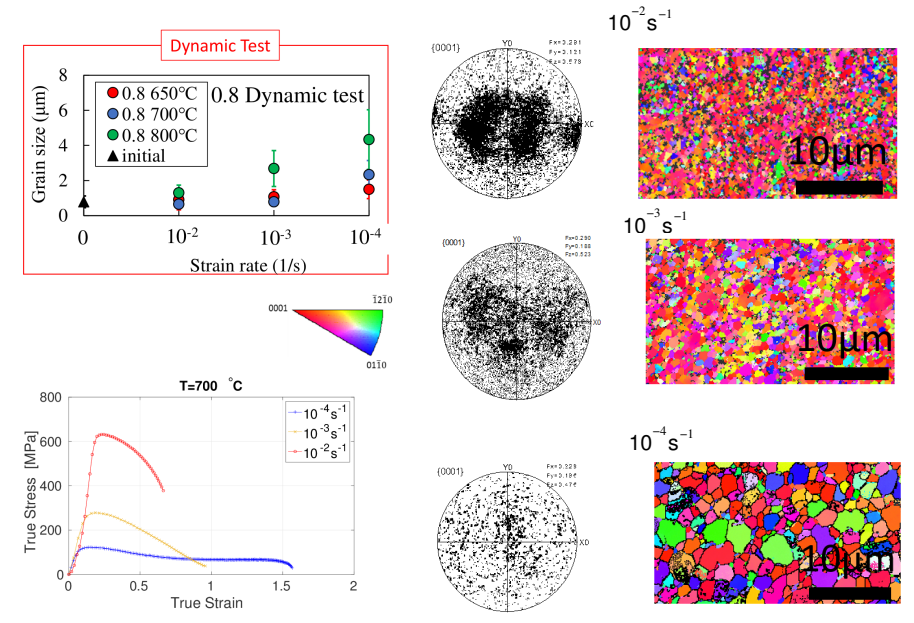

Fig. 2: Grain size evolution observed during the tensile test for an intial average grain of $0.8 \mu m$, several temperature levels (from $650^{\circ} \mathrm{C}$ to $800^{\circ} \mathrm{C}$ ) and strain rates (from $10^{-4} \mathrm{~s}^{-1}$ to $10^{-2} \mathrm{~s}^{-1}$ ); influence of the loading path on the texture evolution and its interaction with the strain-stress response at $700^{\circ} \mathrm{C}$

growth effect. The results provided by the tensile tests enhance this observation with a strain hardening occurring first and inducing a higher stress level at $5.10^{-4} s^{-1}$ compared to $10^{-3} s^{-1}$ before a stress decrease and an additional steady state behavior.

\section{Behavior Modeling}

In this section, constitutive equations are identified from the tests performed on the starting microstructure of $3 \mu \mathrm{m}$. In the first stage, the parameters of evolution laws $[2,4,5]$ able to describe both static and dynamic grain growth are identified. The identification procedure was not easy because, depending on the test conditions, interactions between grain growth and dynamic recrystallization can occur sequentially. Therefore, test conditions only inducing grain growth were selected to determine the parameters. Then, some data from the literature were used to validate the methodology [5]. The models used are recalled in Eq. 1 (static case) and Eq. 2 (dynamic case). $A_{1}, A_{2}, m_{1}, m_{2}$ and $n_{1}$ are temperature dependent parameters and $\dot{p}$ is the cumulative inelastic strain rate.

$$
\begin{gathered}
\dot{d}_{s t a}=A_{1} d^{-m_{1}} \\
\dot{d}_{d y n}=A_{2} d^{-m_{2}} \dot{p}^{n_{1}}
\end{gathered}
$$

The model predictions are in quite good agreement from $730^{\circ} \mathrm{C}$ to $960^{\circ} \mathrm{C}$ in the case of the static tests. Fig. 2a shows the comparison between computed results and experiment for the dynamic tests and the higher temperatures $\left(T \geq 920^{\circ} \mathrm{C}\right)$ where grain growth is predominant. The results are compared to the empirical law provided in the works of Semiatin [8]. The tensile tests performed at lower temperatures $\left(T \leq 840^{\circ} \mathrm{C}\right)$ are used to identify the dynamic recrystallization phenomenon. In this case, the evolution law is first calibrated using Eq. 3. Fig. $2 \mathrm{~b}$ presents some results provided at $\mathrm{T}=730^{\circ} \mathrm{C}$ and $840^{\circ} \mathrm{C}$.

$$
\dot{d}_{d r x}=-A_{3} d^{m_{3}} \dot{p}^{n_{2}}
$$

The constitutive equations consider an internal variable $d$ related to the microstructural evolution. This variable is defined by the contribution due to the dynamic recrystallization and the grain growth effects under static and dynamic conditions (See Eq. 4). According to the previous discussion, the influence of each contribution strongly depends on the test conditions (temperature and strain rate). 
Table 1: Constitutive equations used in the behavior model formulation

\begin{tabular}{|c|c|}
\hline Yield function $f$ & $f=\sigma-R-\sigma_{0}$ \\
\hline Isotropic Hardening $R$ & $R=b_{1} Q \rho ; \quad \dot{\rho}=\underbrace{\left(\frac{d}{d_{0}}\right)^{\gamma}}_{\text {initial GS }} \cdot \underbrace{\left(1-b_{1} \rho\right) \dot{p}}_{\text {stationary or hardening }}-\underbrace{b_{2} \rho \frac{\dot{S}}{1-S}}_{\text {softening }}$ \\
\hline Volume fraction of recrystallized material $S$ & $\dot{S}=\frac{q_{1} \rho^{q_{2}}}{d}(1-S)^{q_{3}}(0.1+S)$ \\
\hline Associated flow rule & $\left|\dot{\varepsilon}_{\text {in }}\right|=\dot{p} ; \quad \dot{p}=\alpha_{1} \sinh \left(\alpha_{2}\langle f\rangle\right)\left(\frac{d}{d_{0}}\right)^{\mu} ; \quad<.>$ the Macaulay brackets \\
\hline Stress rate & $\dot{\sigma}=E\left(\dot{\varepsilon}_{\text {tot }}-\dot{\varepsilon}_{\text {in }}\right)$ \\
\hline Strain hardening (when DRX does not occur) & $Q=Q_{0} e^{\beta_{0}<\Delta d>\text { where } \Delta d=d-d_{0}}$ \\
\hline
\end{tabular}

$$
\dot{d}=\dot{d}_{s t a}+\dot{d}_{d y n}+\dot{d}_{d r x}
$$

In the next step, the microstructural variable is coupled with a behavior model that is able to describe the viscoplastic behavior and take into account the interaction with the strain-stress response of the material. Table 1 summarizes the model components. The evolution equation related to the description of the dynamic recrystallization effect (Eq. 3) is modified to be written as a function of the volume fraction of recrystallized material $S$ (see Eq. 5) [4]. In this case, the initial parameter calibration is used to determine the final parameters $A_{3}, m_{3}$ and $m_{4}$.

$$
\dot{d}_{d y n}=-A_{3} \dot{S}^{m_{4}} d^{m_{3}}
$$

(a)

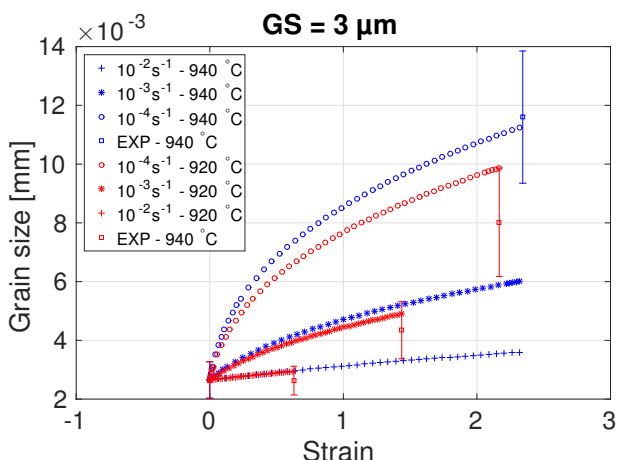

(b)

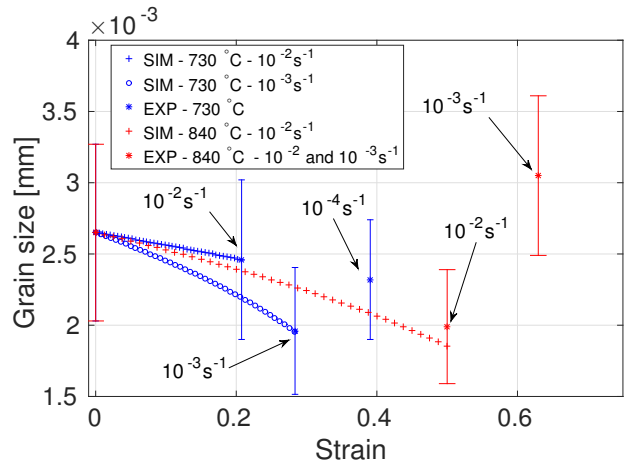

Fig. 3: Comparison between computed grain growth curves and experiment under dynamic conditions from $920^{\circ} \mathrm{C}$ to $940^{\circ} \mathrm{C}$ (a) and from $730^{\circ} \mathrm{C}$ to $840^{\circ} \mathrm{C}$ (b).

The behavior model considers a von Mises yield criterion in order to describe the transition between elastic and viscoplastic behavior. $\sigma_{0}$ is the initial elasticity limit of the material. The criterion evolution is defined through an isotropic hardening variable $R$. Three contributions are introduced into the evolution equation of the internal variable $\rho$ associated with the variable $R$.

The first term allows the influence of several starting microstructures on the hardening evolution to be taken into account, while the second term provides a description of the stationary behavior of the hardening and the last one enables consideration of a softening term induced by a dynamic recrystallization effect. $d_{0}$ is the initial grain size and $b_{1}, b_{2}$ and $Q$ are temperature-dependent parameters. $S$ is the recrystallized volume fraction variable, which is formulated as a function of the internal variable $\rho$ and of the product of two terms related to the fraction of mobile boundaries. Its form is deduced from several previous investigations $[4,6]$. The associated flow rule, able to account for the strain rate 
sensitivity of the alloy, is written using a hyperbolic sine form of the yield function $f$, where $\alpha_{1}, \alpha_{2}$ and $\mu$ are temperature-dependent coefficients. The stress rate equation is classically written in uniaxial form and considers a partition of the total strain rate into elastic and inelastic parts. $E$ is Young's modulus. Lastly, at high temperature, when a significant grain growth effect is observed, the asymptotic value $Q$ of the isotropic hardening variable $R$ is considered as a function of the grain size range $\Delta d$ through two other coefficients $Q_{0}$ and $b_{0}$. The calibration of each model parameter was performed at each temperature level. Firstly, the microstructural coefficients were determined from the analysis of the microstructural evolution. Then, the tensile tests provided the hardening and viscous parameters. Lastly, a fine tuning process combining a global and a local optimization procedure (Genetic Algorithm and Levenberg-Marquardt methods) was implemented. Fig. 4 illustrates the model predictions at $730^{\circ} \mathrm{C}$ (a-b) and $840^{\circ} \mathrm{C}$ (c-d). The computed results are in a good agreement with the experiment, both in terms of grain size evolution under dynamic conditions where mainly dynamic recrystallization occurs, and in the strain-stress response. Fig. 5 shows the model capabilities for other test conditions from $920^{\circ} \mathrm{C}$ to $960^{\circ} \mathrm{C}$ where grain growth is predominant, involving a significant strain hardening.

(a)

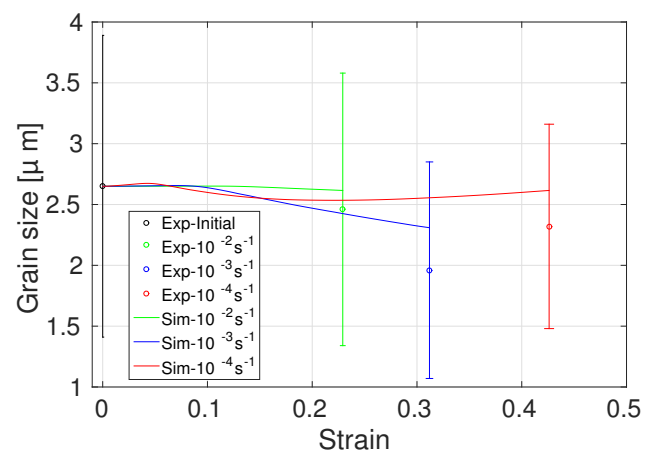

(c)

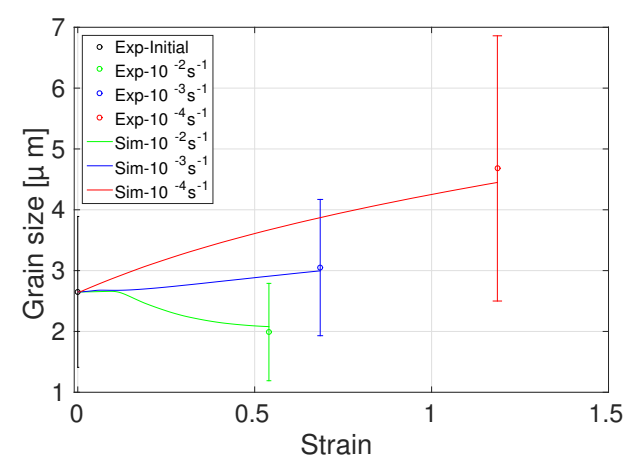

(b)
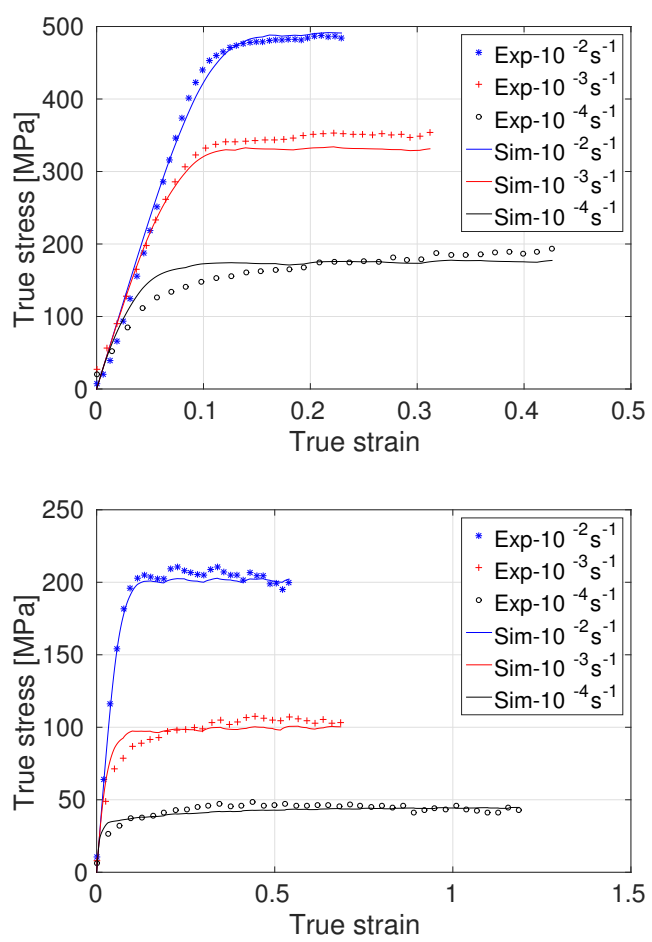

Fig. 4: Model predictions at $T=730^{\circ} \mathrm{C}$ (a-b) and $T=840^{\circ} \mathrm{C}$ (c-d)

\section{Summary}

The following summary and conclusions can be drawn from this work:

- the mechanical behavior of Ti6242 titanium alloy was investigated under hot forming conditions

- constitutive equations were identified to describe the mechanical response as well as the associated microstructural evolutions.

- several test conditions were taken into account, which induced various mechanisms (grain growth, DRX) involving hardening or softening.

- complex interactions can occur at intermediate temperatures and should be investigated in more detail in further studies in order to enhance the model capabilities. 
(a)

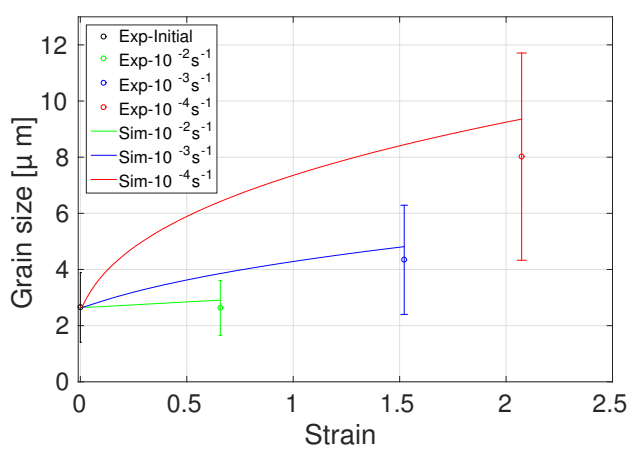

(c)

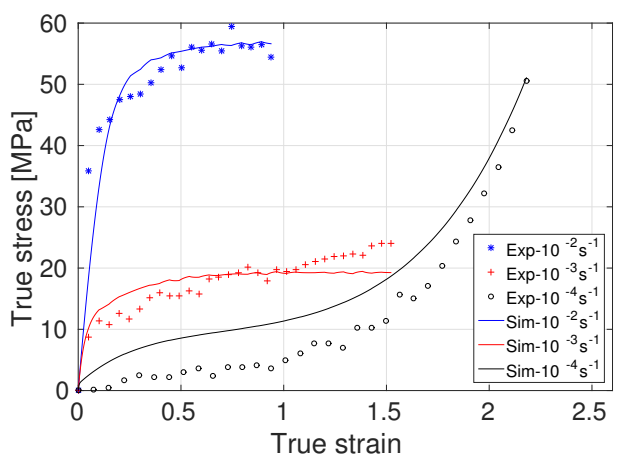

(b)

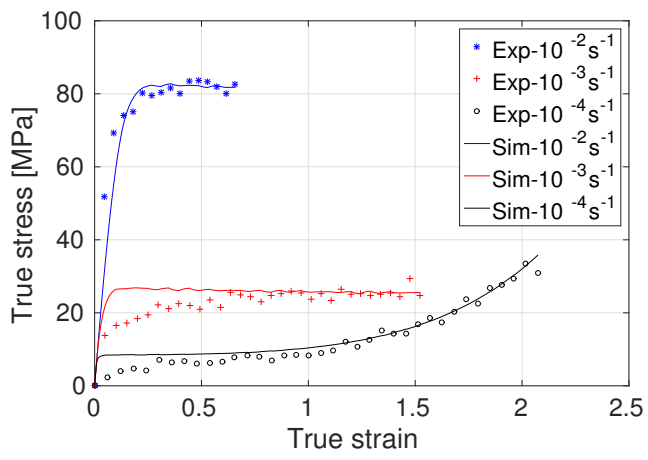

(d)

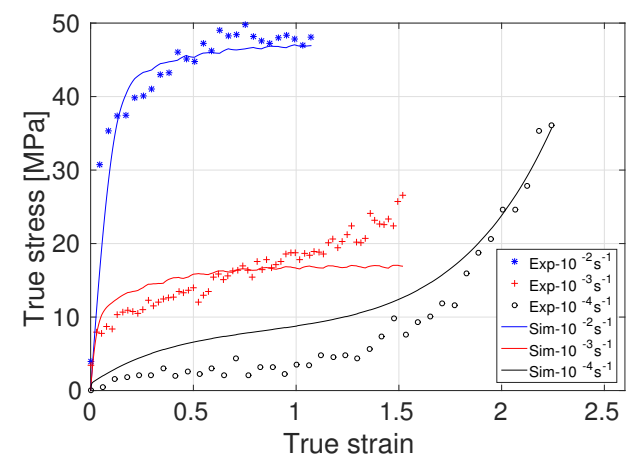

Fig. 5: Model predictions at $T=920^{\circ} \mathrm{C}$ (a-b), $T=940^{\circ} \mathrm{C}$ (c) and $\mathrm{T}=960^{\circ} \mathrm{C}$ (d)

\section{References}

[1] E-L. Odenberger, R. Pederson, Mats Oldenburd, Thermo-mechanical material response and hot sheet metal forming of Ti6242, Mat. Sc. And Eng. A. 489 (2008) 158-168.

[2] V. Velay, H. Matsumoto, V. Vidal, A. Chiba, Behavior modeling and microstructural evolutions of Ti-5Al-4V alloy under hot forming conditions, Int. J. of Mech. Sc.. 109-109 (2016) 1-13.

[3] M.W. dos Santos, V. Velay, V. Vidal, G. Bernhart, G. F. Batalha, H. Matsumoto, Mechanical behavior of a Ti-6Al-4 V titanium alloy with microstructural evolution modeling under hot and superplastic conditions, Mat.-wiss. u. Werkstofftech., 48 (2017) 952-961.

[4] E. Alabort, D. Putman, R.C. Reed, Superplasticity in Ti-6Al-4V: Characterization, modelling and applications, Acta Mat. 95 (2015) 428-442.

[5] J. Lin, T. Dean T, Modeling of microstructure evolution in hot forming using unified constitutive equations, J. Mater. Process. Technol. 167 (2-3) (2005) 354-362.

[6] J. Lin, Y. Liu, D.C. Farugia, M; Zhou, Development of dislocation-based unified material model for simulating microstructure evolution in multipass hot rolling, Phil. Mag. 85 (2005) 1967-1987.

[7] L. Yang, N. Li, B. Wang, J. Lin, H. Zhao, W. Ma, Unified constitutive modelling for two-phase lamellar titanium alloys at hot forming conditions, Manuf. Rev. 3 (2016).

[8] S.L. Semiatin, P.N. Fagin, J.F. Betten, A.P. Zane, A.K; Ghosh, G.A. Sargent. Plastic flow and microstructure evolution during low-temperature superplasticity of ultrafine Ti-6Al-4V sheet material, Metall Mater Trans A - Phys Metall Mater Sci 41A(2) ( 2010) 499-512. 